\title{
COMMUNICABLE DISEASES REPORT, NSW: MARCH 2003
}

\section{TRENDS}

Notifications of communicable diseases received through to January 2003 appear in Table 2 and Figure 1.

\section{BLOOD-BORNE AND SEXUALLY TRANSMISSIBLE INFECTIONS}

The number of notifications of gonorrhoea and chlamydia continues to rise. Notifications of gonorrhoea have reached their highest levels since laboratory reporting began in 1991. Notifications of chlamydia have reached their highest levels since reporting began in 1999.

There are, however, important differences in the epidemiology of these diseases in NSW. Chlamydia is approximately four times more frequently notified than gonorrhoea (5621 versus 1469 cases in 2002). Data for the three months to January 2003 show that when compared with gonorrhoea cases, chlamydia cases tend to be younger ( 52 per cent were under 25 years of age compared with 21 per cent of gonorrhoea cases), more commonly female (53 per cent compared with seven per cent) and more widely distributed about the state (38 per cent live in rural areas compared with only 14 per cent of gonorrhoea cases).

These data and anecdotal reports indicate that chlamydia is more common in younger heterosexually-active people than in men who have sex with men, while gonorrhoea is more common in men who have sex with men. Both infections can be prevented through practicing safe sex such as using condoms with sexual partners. Transmission can be restricted through the early diagnosis and treatment of cases, and by screening and treating the infected sexual partners of cases.

Patients can talk in confidence to a general practitioner or local sexual health service to obtain more information about screening for these diseases. Clinicians can call their local sexual health service for advice and assistance with partner contact tracing and screening. These services are listed under Sexual Health Clinics in the White Pages.

\section{VECTOR-BORNE DISEASES}

Over the summer relatively few arbovirus infections were notified. Barmah Forest virus infection however continues to predominate, especially on the coastal areas in the north of the state.

\section{ZOONOSES}

Reports of Q fever have increased in recent months. This increase is most likely to be related to increased Q fever immunisation-related screening, although a real increase in disease transmission cannot be ruled out. In January, cases were notified predominantly from the rural areas in the west and north of the state.
Q fever can be transmitted to people from farm and native animals, and those most at risk are workers in the meat and farming industries. The Commonwealth-funded Q fever program targets people who are at increased risk, and involves pre-immunisation screening for prior infection. For more information, contact your local Public Health Unit.

\section{REPORT OF AN OUTBREAK OF PSITTACOSIS ASSOCIATED WITH WILD BIRDS INTHE BLUE MOUNTAINS}

\section{Background}

Psittacosis is caused by infection with the bacteria Chlamydophila psittaci. It is considered a relatively rare disease in humans, and is usually spread to humans by inhalation of bacteria from dried bird droppings or other particles from infected birds. Psittacosis became a notifiable disease in NSW in 2001. In that year, 36 cases were notified.

The available literature suggests that pet birds and aviaries are the source of most infections in humans. ${ }^{1,2}$ Prior to the outbreak in the Blue Mountains, the largest reported psittacosis outbreak in Australia occurred in Bright, Victoria, where 16 cases were identified. In these cases, illness was associated with mowing or trimming lawns, and gardening, in environments presumed to be infected with droppings and particles from wild birds.

In May 2002, clinicians of the Blue Mountains District Hospital (BMDH) in Katoomba reported an increase in admissions for severe community-acquired pneumonia in previously healthy adults. One clinician suggested a link to human contact with sick or dead parrots. Investigations were undertaken to confirm the existence of an outbreak, to identify its cause and any potentially-modifiable risk factors. This report provides a summary of the initial results of the outbreak investigation, and the preliminary recommendations.

\section{Methods}

Review of past admissions for pneumonia

Rates of admission to hospital for pneumonia in residents of the Blue Mountains were reviewed for the period 19952000 .

\section{Case identification}

The causative organism for cases of pneumonia admitted to hospital between March and June 2002 was sought through collection and testing of acute and convalescent serology. Possible cases were identified both retrospectively (March to May) and prospectively (June), based on the following case definition:

- admitted to hospitals in the Blue Mountains or adjacent areas with pneumonia;

- resident of the Blue Mountains area; 
- 15-75 years of age;

- radiological changes consistent with pneumonia;

- no medical history of heart failure or chronic obstructive pulmonary disease.

A confirmed case of psittacosis was defined as:

- possible cases in whom Chlamydophyla psittaci infection was confirmed by serology or polymerase chain reaction (PCR) testing. A positive serological result included a seroconversion with a four-fold or greater rise in titre, single high titre, or static high titre.

The Wentworth Area Public Health Unit contacted cases and arranged for blood collection at special clinics at the Blue Mountains District Hospital. Blood was tested for influenza, mycoplasma, chlamydia, legionella, adenovirus and $\mathrm{Q}$ fever. Throat swabs were taken from some of the later cases and these specimens were examined using PCR testing.

\section{Case control study}

A case-control study was undertaken, using confirmed or possible cases that had not tested negative at the time of the study. Reported exposures in these 'study' cases were compared with controls, who were randomly selected from the Blue Mountains telephone book. Interviews of cases and controls were conducted from the CATI (Computer Analysis of Telephone Interviews) facility within the NSW Department of Health.

\section{Testing of birds}

Sick or dead birds found in the Blue Mountains region during June were also submitted for testing for Chlamydophila psittaci.

\section{Results}

Past admission for pneumonia

A review of admissions for pneumonia during 1995-96 to 1999-00 found significantly higher rates of admission for residents of the upper Blue Mountains, when compared to those of residents of the lower regions of the Blue Mountains and the NSW state average. Overall, residents of the upper Blue Mountains had a standardised separation ratio of 176.6 (95 per cent CI 161.2-193.2) for pneumonia over this period, compared to 91.6 (95 per cent CI 80.6103.6) for residents of the lower Blue Mountains.

\section{Case identification}

Between 1st March and 30th June 2002, 95 possible cases were identified. Of these possible cases, 77 (81 per cent) resided in the upper Blue Mountains (Bullaburra to Mount Victoria).

Serological results were obtained for 87 possible cases. Sixty of these cases (69 per cent) were positive for Chlamydophyla psittaci. Of the 27 cases (31 per cent) who tested negative for psittacosis, seven had an alternative diagnosis made by the doctor on receipt of the laboratory results. Fifty-one of the laboratory confirmed cases (85 per cent) were residents of the upper Blue Mountains.

Case control study

Preliminary analysis of the case control study included 62 cases and 310 controls. These findings are presented in Table 1. Illness was associated with: being male, aged 50-64 years, and residing in the middle or upper Blue Mountains.

Compared with no contact, direct contact with wild birds was also associated with illness. Indirect contact with wild birds was not significantly associated with illness, except

\section{TABLE 1}

FREQUENCIES OF EXAMINED RISK FACTORS FOR PSITTACOSIS IN CASES AND CONTROLS, BLUE MOUNTAINS, 2002

\begin{tabular}{|c|c|c|c|c|c|c|}
\hline Variable & \multicolumn{2}{|c|}{ Cases } & $\begin{array}{c}\text { Cont } \\
N\end{array}$ & Controls & $\begin{array}{l}\text { Crude Odds } \\
\text { Ratio }\end{array}$ & $\begin{array}{c}95 \% \\
\text { Confidence Interval }\end{array}$ \\
\hline Upper Blue Mountains resident & 49 & $(80)$ & 104 & (34) & 20.4 & $7.0-58.0$ \\
\hline $50-64$ years of age & 32 & $(52)$ & 89 & $(29)$ & 8.6 & $2.5-29.3$ \\
\hline Male & 37 & $(60)$ & 125 & $(40)$ & 2.2 & $1.2-4.0$ \\
\hline \multicolumn{7}{|l|}{ Direct contact with birds specifically: } \\
\hline Touching bird feathers & 14 & $(23)$ & 22 & $(7)$ & 3.8 & $1.7-8.4$ \\
\hline Touching bird droppings & 20 & $(32)$ & 33 & $(11)$ & 4.0 & $2.0-8.0$ \\
\hline Handling dead birds & 10 & $(16)$ & 11 & (4) & 5.2 & $1.9-14.2$ \\
\hline Watch birds in garden & 44 & $(71)$ & 165 & $(53)$ & 2.1 & $1.1-4.1$ \\
\hline Seeing dead birds & 12 & $(19)$ & 22 & $(7)$ & 3.1 & $1.3-7.1$ \\
\hline Direct contact with wild birds-any of the above & 30 & $(48)$ & 52 & $(17)$ & 6.6 & $3.1-13.8$ \\
\hline Mowing without catcher & 26 & $(42)$ & 65 & $(21)$ & 2.4 & $1.3-4.5$ \\
\hline Use compost & 19 & $(32)$ & 49 & $(16)$ & 2.5 & $1.2-4.8$ \\
\hline Current smoker & 2 & (3) & 58 & (19) & 0.1 & $0.02-0.6$ \\
\hline
\end{tabular}


for specific activities such as mowing lawns without a catcher or using compost.

Testing of birds

Of the five birds submitted for immuno-fluorescent antibody testing, only one young parrot was positive for Chlamydophila psittaci.

\section{Conclusions}

The largest reported outbreak of psittacosis among humans in Australia to date occurred in the Blue Mountains between March and June 2002. Preliminary analysis indicates that direct contact with wild birds, and lawn mowing without a catcher, were associated with illness. Exposure to domestic and farm birds was not associated with illness.

The investigation of this outbreak has provided new information about psittacosis, and has reinforced the finding from the 1996 outbreak in Bright that large outbreaks of infection in humans can be associated with wild birds, rather than with pet birds and aviaries. ${ }^{3}$

The risk of infection in this outbreak appeared to be limited to residents of the mid-to-upper Blue Mountains, and to the March-June period of 2002. However, the finding of increased rates of pneumonia in the upper Blue Mountains at similar periods during previous years raises the possibility that psittacosis recurs seasonally in this area. Anecdotal reports from members of the local Wildlife and Information Rescue Service (WIRES), which suggest clinical signs of psittacosis in wild birds during autumn in previous years, adds support to this hypothesis. Active surveillance for cases of pneumonia, together with laboratory testing for psittacosis in both birds and humans, will be continued over the coming year in an effort to answer this question.

These investigations will also examine why residents of the upper Blue Mountains were most at risk of psittacosis in autumn 2002, and of hospitalisation with pneumonia in the autumn of recent years. Surveillance of both birds and humans will be undertaken to determine if there are conditions in the upper Blue Mountains with regard to the environment (for example, weather patterns and bird habitats), the birds (for example, the density and distribution) or human factors (for example, the distribution or behaviours of susceptible populations) that facilitate psittacosis transmission. Identification of such factors can help to inform future prevention strategies, both locally and in other areas with a similar ecology.

\section{Acknowledgements}

Thanks to James Branley, Dominic Dwyer and staff ICPMR, Patricia Correll, George Truman, Lisa Allchin, Blue Mountains District Hospital staff.

\section{References}

1. Harris RL, Williams TW Jr. Contribution to the question of Pnuemotyphus: A discussion of the original article by J Ritter in 1880. Rev Infectious Diseases 1985;7(1):119-22.

2. Schlossberg D, Delgado J, Morre MM, Wishner A, Mohn J. An epidemic of avian and human psittacosis. Arch Intern Med 1993;153:2594-96.

3. Williams J, Tallis G, Dalton C, Ng S, Beaton S, Catton M., Elliott J, Carnie J. Community Outbreak of psittacosis in a rural Australian town. Lancet 1998;35:1697-9.

\section{RESPIRATORY DISEASES}

Notifications of meningococcal and invasive pneumococcal disease cases approached their usual low points in January.

\section{VACCINE-PREVENTABLE AND OTHER DISEASES}

No cases of measles have been identified in NSW for over five months now (since August 2002). Notifications of pertussis are at inter-epidemic levels, and only occasional cases of Legionnaires' disease were reported in recent months.

\section{ENTERIC DISEASES}

In January, over 200 notifications of salmonellosis were received. Among these, the most common serovar was $S$. typhimurium (36 per cent).

The national S. potsdam investigation was closed this month. A total of 70 cases were identified as part of the outbreak in November and December. Despite extensive case interviews, the source of the outbreak is unclear.

Four related cases of gastroenteritis (including one case in whose stool Salmonella 4,$12 ; D$ was isolated) were identified in children who shared a common meal at a restaurant in inner Sydney in January. Two separate cases of hepatitis A reported eating at a restaurant in Sydney's south within the same week in December. While there was no proof that these restaurants were responsible for causing these infections, Public Health Unit food inspectors reviewed restaurant food handling procedures to minimise the risk of further cases. 
FIGURE 1

REPORTS OF SELECTED COMMUNICABLE DISEASES, NSW, JANUARY 1998 TO JANUARY 2003, BY MONTH OF ONSET

Preliminary data: case counts in recent months may increase because of reporting delays.

Laboratory-confirmed cases only, except for measles, meningococcal disease and pertussis $\mathrm{BFV}=$ Barmah Forest virus infections, RRV $=$ Ross River virus infections

$\mathrm{LI}=$ Legionella longbeachae infections, $\mathrm{L} p=\mathrm{L}$. pneumophila infections

$\mathrm{Gp} C$ and $\mathrm{Gp} B$ = disease due to serogroup $\mathrm{C}$ and serogroup $\mathrm{B}$ infection,

other/unk $=$ other or unknown serogroups

\begin{tabular}{|rc|}
\hline \multicolumn{2}{|c|}{ NSW population } \\
Male & $50 \%$ \\
$<5$ & $7 \%$ \\
$5-24$ & $28 \%$ \\
$25-64$ & $52 \%$ \\
$65+$ & $13 \%$ \\
Rural* & $42 \%$ \\
\hline
\end{tabular}
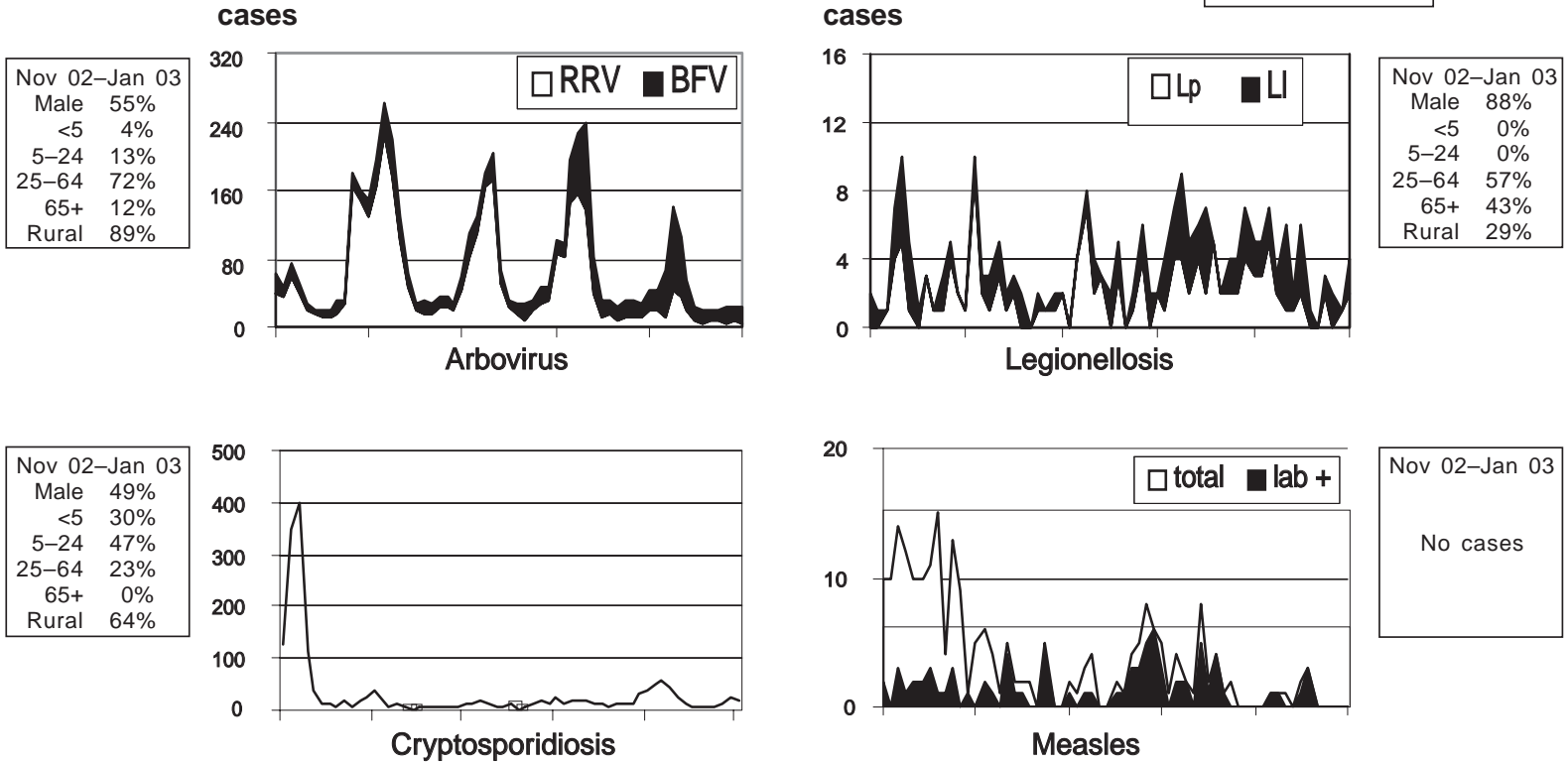

Nov 02-Jan 03

No cases
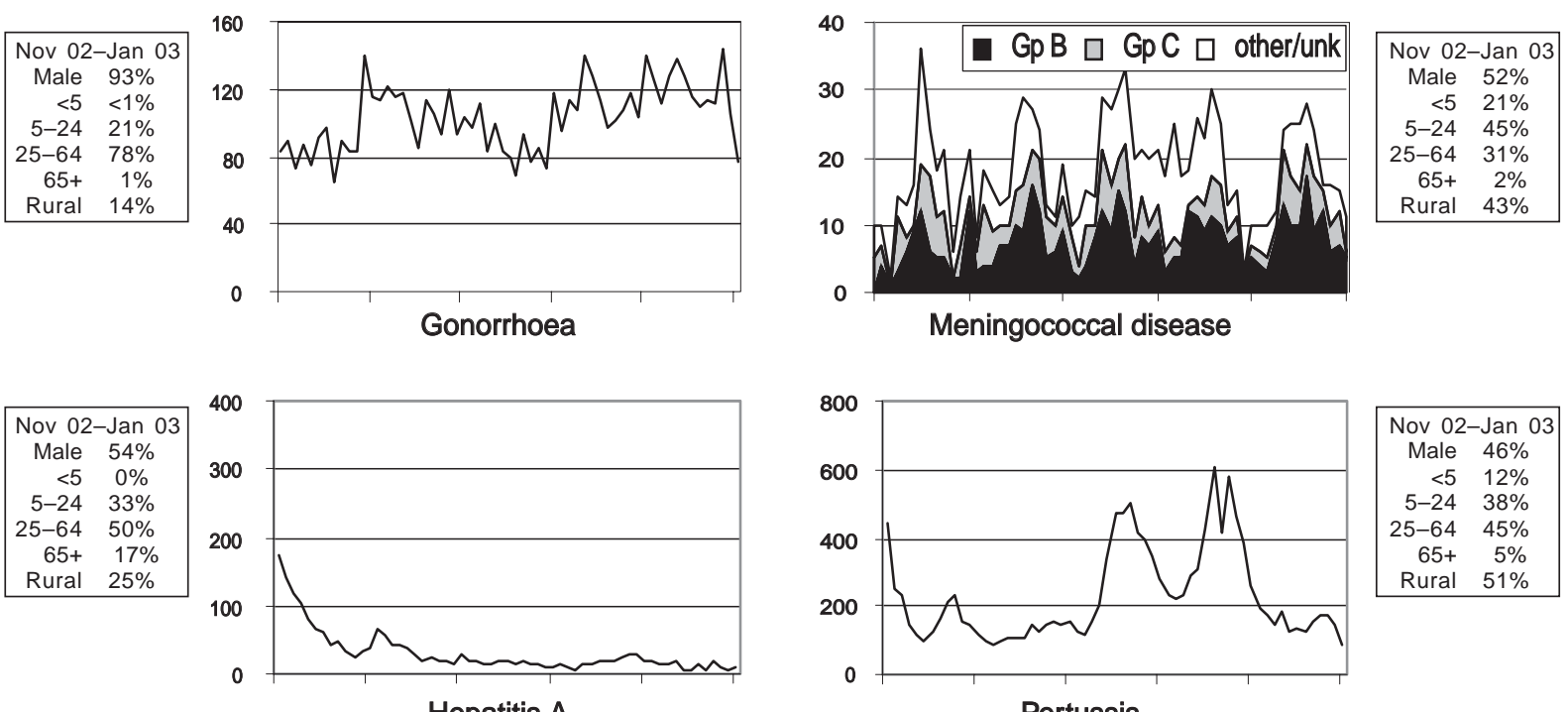

Hepatitis A

Pertussis

\begin{tabular}{|rc|}
\hline \multicolumn{2}{|c|}{ Nov 02-Jan 03} \\
Male & $56 \%$ \\
$<5$ & $31 \%$ \\
$5-24$ & $8 \%$ \\
$25-64$ & $33 \%$ \\
$65+$ & $29 \%$ \\
Rural & $39 \%$ \\
\hline
\end{tabular}
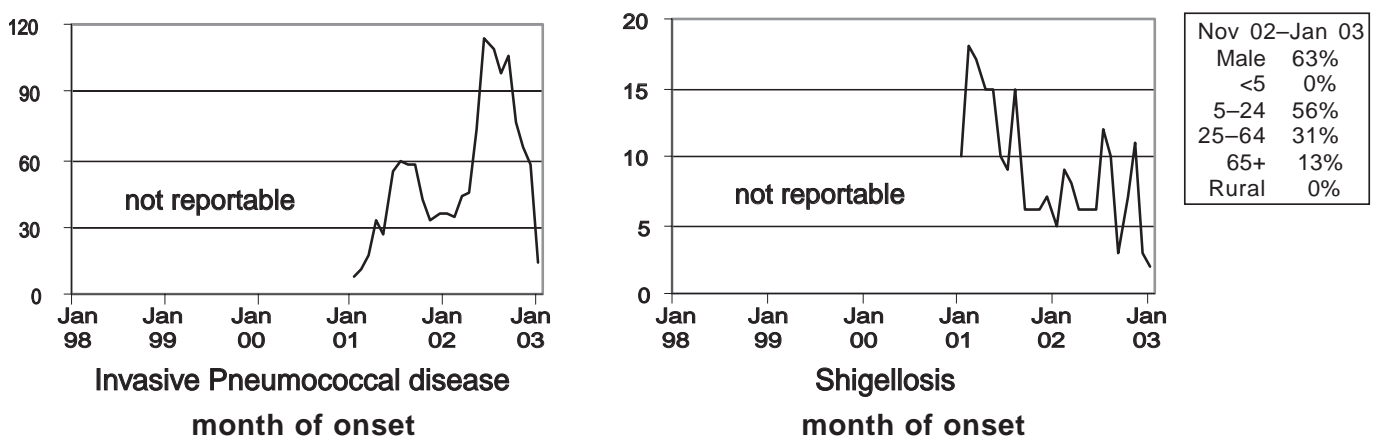


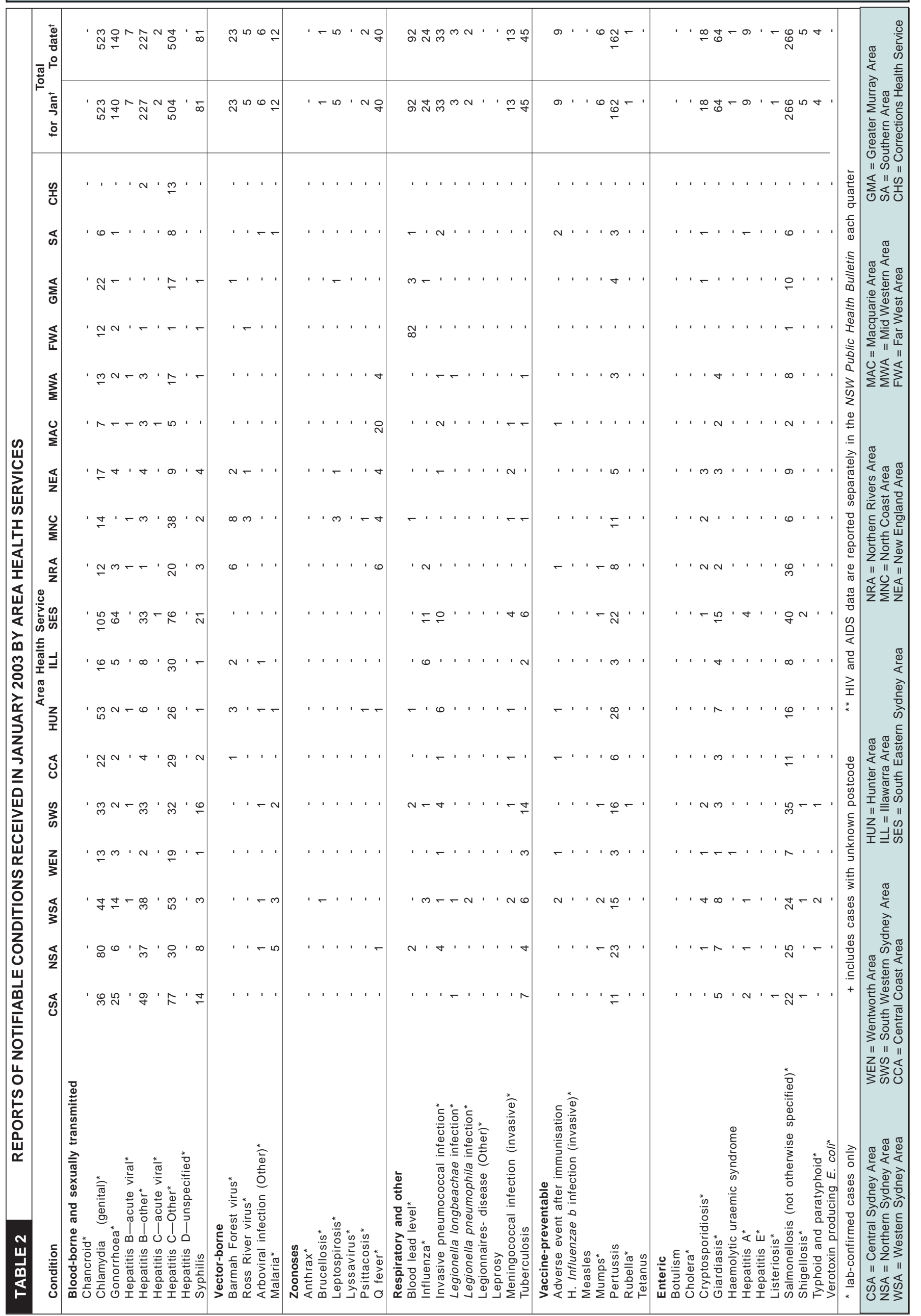

